\title{
ARTIGO
}

dO https://doi.org/10.22481/praxisedu.v16i39.4779

\section{POLÍTICAS DE PRIVATIZAÇÃO NA EDUCAÇÃO PÚBLICA E A ATUAÇÃO DE GRUPOS EDUCACIONAIS PRIVADOS}

\author{
PRIVATIZATION POLICIES IN PUBLIC EDUCATION AND THE ACTION OF \\ PRIVATE EDUCATIONAL GROUPS
}

\author{
POLÍTICAS DE PRIVATIZACIÓN EM LA EDUCACIÓN PÚBLICA Y LA ACTUACIÓN \\ DE GRUPOS EDUCACIONALES PRIVADOS
}

Thaís Godoi de Souza

Universidade Estadual de Maringá - Brasil

Jani Alves da Silva Moreira

Universidade Estadual de Maringá - Brasil

\begin{abstract}
Resumo: O texto tem como objetivo analisar as políticas de privatização na educação pública a partir da atuação de grupos educacionais privados de educação básica no Brasil e suas áreas de ação, a fim de identificar a oferta de seus serviços e produtos para a educação pública. Trata-se de uma pesquisa exploratória e de análise documental a partir da seleção e estudo das seguintes empresas: Pearson, Somos Educação, Santillana, Objetivo, Positivo, Etapa e Opet e também, o Relatório do Observatório da Educação (2015). Constatou-se que os grupos educacionais são empresas que veem na educação brasileira um mercado em expansão e divulgam a ideia de qualidade de seus serviços. Estes grupos utilizam de um discurso no qual o serviço privado tem sido sinônimo de eficiência e qualidade, enfatizam que os estados e municípios que adotam estes sistemas têm grandes chances de alcançarem bom índices nas avaliações nacionais e internacionais, como o Índice de Desenvolvimento da Educação Básica/Ideb e Programa Internacional de Avaliação de Estudantes/Pisa.
\end{abstract}

Palavras chave: Educação básica pública; Grupos educacionais privados; Políticas de privatização.

Abstract: The text aims to analyze the privatization policies public education based on the performance of private educational groups basic education in Brazil and their areas of action, in order to identify the offer of its services and products for public education. This is an exploratory research and documentary analysis based on the selection and study of the following companies: Pearson, Somos Education, Santillana, Objective, Positivo, Etapa and Opet and also the Report of the Education Observatory (2015). It was foud that the educational groups companies that operate in Brazil see in education an expanding market and spread the ideia of quality of their services. These groups use a discourse in whicht the private service has been synonnymous with efficiency and quality, emphasizing that the states and 
municipalities that adopt these systems have a good chance of achieving good indexes in national and international evaluations, such as the Basic Education Development Index/Ideb and the International Student Assessment Program/Pisa.

Keywords: Public basic education. Private educational groups. Privatization policies.

Resumen: El texto tiene como objetivo analizar las políticas de privatización de la educación pública basadas en el desempeño de grupos educativos de educación básica en Brasil y sus áreas de acción, a fin de identificar la oferta de sus servicios y productos para la educación pública. Esta es una investigación exploratoria y de análisis documental basado en la selección y estudio de las siguientes empresas: Pearson, Somos Educación, Santillana, Objetivo, Positivo, Etapa e Opet y también, el Informe del Observatorio de la Educación (2015). Se constató que los grupos educativos/empresas que actúan en Brasil ven en la educación un mercado en expansión y divulgan la idea de la calidad de sus servicios. Estos grupos utilizan un discurso en que el servicio privado há sido sinonimo de eficiencia y calidad, enfatizando que los Estados y municipios que adoptan estos sistemas tienen grandes posibilidades de alcanzar buenos índices en las evaluaciones nacionales y internacionales, como el Índice de Desarrollo de la Educación Basica/Ideb y Programa Internacional de Evaluación de Estudiantes/Pisa.

Palabras clave: Educación básica pública. Grupos educativos privados. Políticas de privatización.

\section{Introdução}

O objetivo deste texto é analisar a atuação de grupos educacionais privados atuantes na educação básica no Brasil e suas áreas de ação, a fim de identificar a oferta de seus produtos para a educação pública.

Trata-se de um estudo exploratório sobre as políticas de privatização na educação pública a partir da atuação dos principais grupos educacionais privados e a relação com as parcerias público-privadas. Além da constatação concreta no ambiente de trabalho da atuação das pesquisadoras em redes de ensino, na formação continuada de professores do sistema público e privado, notou-se também um grande número de produções científicas no banco de teses e dissertações da Capes que abordam a temática da atuação do terceiro setor e empresas na educação. As discussões dessas pesquisas suscitam para além da compreensão sobre as parcerias, elas destacam, a presença atuante de redes de instituições e sujeitos privados e públicos organizados em torno do slogan melhoria da qualidade da educação. Todavia, fica mais perceptível que esse slogan é mais frequente quando se trata de políticas para a educação básica. 
Ao buscar identificar outros estudos sobre a atuação dessas redes na educação básica brasileira, descobriu-se a existência da atuação de grandes empresas interessadas no mercado da educação básica, pois o número de matrículas nas etapas de educação infantil, fundamental e médio (ensino regular) é superior ao ensino superior no Brasil. No censo escolar de 2017, o número de matrículas na educação infantil foi de 8,50 milhões, 27,3 milhões no ensino fundamental e 7,93 milhões no ensino médio, totalizando 48,6 milhões de matrículas no ensino regular público e privado (INEP, 2017a, s/p).

No ensino superior é possível identificar que houve crescimento de matrículas no Brasil de 1994 a 2002, de 1.661 a 3.840 mil matrículas de graduação presencial, sendo que em 2002 o ensino superior privado respondia aproximadamente por $70 \%$ das matrículas (DOURADO, 2011). De 2003 a 2010, ampliou-se o número de matrículas em instituições privadas de ensino superior por meio do financiamento público do governo federal, FIES ${ }^{1}$ e o ProUni (Programa Universidade para Todos). No ano de 2017, o setor privado deteve 75,3\% (6.242.307 milhões) das matrículas em cursos de graduação enquanto a rede pública totalizou 24,7\% (2.045.356 milhões) (INEP, 2017b, p.14)

Essa elevação de matrículas na educação superior permitiu a formação e qualificação de muitos jovens trabalhadores assalariados, mas também, a conseqüência das políticas e parcerias entre o público e o privado ocasionou a redenção das instituições privadas de educação superior que beiravam a falência.

As IES privadas cresceram abundantemente no Brasil e se transformaram em um mercado epidêmico, tanto no ensino presencial, quanto na modalidade a distância. E com isso grupos educacionais cresceram e se proliferaram como é o caso da Kroton S.A, atual Cogna Educação, a qual se tornou uma empresa de capital aberto em 2007. Este grupo se expandiu e ansiava por maior crescimento, dessa forma visou e tentou adquirir outra empresa gigante da educação superior, a Estácio.

Todavia, essa negociação foi vetada, em 2017, pela Superintendência Geral do Conselho Administrativo de Defesa Econômica do governo federal, com o argumento de que a operação aumentaria o poder de mercado da Kroton $^{2}$ e reduziria o nível de rivalidade no

\footnotetext{
1 "Em 1999, foi criado o Fundo de Financiamento ao Estudante do Ensino Superior, atualmente chamado de Fundo de Financiamento Estudantil (Fies), com o objetivo de financiar a graduação de estudantes matriculados em cursos superiores presenciais, não gratuitos e com avaliação positiva nos processos de avaliação conduzidos pelo Ministério da Educação" (BRASIL, 2018, s/p). Contudo, foi em 1975 que o Brasil criou o Programa de Crédito Educativo (CREDUC).

${ }^{2}$ Em outubro de 2019, a Kroton assumiu um novo nome e estrutura, no qual passou a ser denominada Cogna Educação e composta por 4 instituições: Kroton, Platos, Saber e Vasta/Somos Educação.
} 
mercado, bem como "[...] o ato de concentração gera elevados marketshares ${ }^{3}$ e monopólios em diversos mercados locais" (CADE, 2017, s/p). Como não foi possível comprar o restante das IES privadas no Brasil, o grupo Kroton caminhou para a educação básica comprando parte da empresa Somos Educação, o qual oferece diversos serviços a educação básica, como sistemas de ensino (Anglo, pH, Ser, Geo, Maxi, Ético, Pitágoras e rede Cristã), editoras (Ática, Scipione, Saraiva e Atual) e escolas de idiomas (Red Balloon).

Grupos educacionais privados miram a educação básica como um mercado profícuo para suas ações de vendas de apostilas, livros, formação de professores, gestores, softwares, projetos, consultorias, assessorias, entre outros (ADRIÃO ET AL, 2015; ADRIÃO, 2016; ADRIÃO 2017). Percebe-se que o Estado nesse cenário atua como instituição responsável por favorecer incentivo ao processo de acumulação capitalista e à regulação dos mecanismos legais, associando-se de forma estreita com a privatização da educação.

Para dar conta do proposto elencou-se como fontes prioritárias os trabalhos de Ball e Yodell (2007), os sítios eletrônicos oficiais das empresas selecionadas e o relatório de pesquisa de Adrião et al (2015). Neste artigo aborda-se sobre o capitalismo financeiro e os processos de privatização da educação básica pública, a atuação dos principais grupos educacionais privados que vendem seus produtos e serviços às redes municipais de ensino. Por fim, analisam-se a influência e as consequências dessa transmissão e repasse dos recursos financeiros públicos ao setor privado.

\section{A ascendência financeira e a privatização da educação}

A política de privatização da educação pública, por meio da compra de sistemas de ensino de grupos educacionais privados, não pode ser entendida de forma singular e nem como algo que afeta apenas as escolas de educação básica e os professores. Pelo contrário, um olhar na perspectiva da historicidade dos fatos indica-nos que se trata de algo já sólido nas relações sociais.

O modo de produzir a vida na contemporaneidade está constituído pelo “[...] drama ambiental, a tragédia social e o caos financeiro" (DOWBOR, 2017, p.36). A administração do planeta favorece uma minoria e os recursos necessários para financiar políticas sociais estão

\footnotetext{
${ }^{3}$ Expressão em língua inglesa que se refere à fatia de mercado que uma empresa, produto ou serviço possui em um determinado período.
} 
“[...] nas mãos de algumas centenas de grupos que sequer conseguem administrar, com um mínimo de competência, as massas de dinheiro que a controlam" (DOWBOR, 2017, p.36).

Em meio a este cenário o desafio atual tem sido reorientar os recursos para financiar as políticas sociais destinadas a gerar uma economia inclusiva (DOWBOR, 2017). Contudo, o modo de produção capitalista se manifesta de forma irracional, possui a capacidade exponencial de produzir mercadorias, conhecimento, concentrar riqueza e a incapacidade de partilhar a produção de bens para o atendimento às necessidades básicas humanas. Nesse meio temos o domínio do capital financeiro especulativo ${ }^{4}$ que nada produz, mas que assalta a capacidade da atividade produtiva.

Dowbor (2017, p.32) alega que as dificuldades atuais que diversos países passam não provêm da falta de recursos financeiros, mas deve-se pela apropriação por corporações financeiras que os usam para especular em vez de investir. "O sistema financeiro passou a usar e drenar o sistema produtivo, em vez de dinamizá-lo". A crise de 2008 tem seus impactos até o atual momento (2019), esta começou a ser enfrentada pelas grandes transferências de recursos públicos ao setor privado. Para manter este sistema de acumulação de papéis financeiros (especulação)

[...] produziu-se paulatinamente a anulação do poder político dos Estados nacionais, transferindo o verdadeiro governo do mundo para os grandes grupos econômicos, hegemonizados pelo capital financeiro, e pelos organismos internacionais que o os representam, mormente a Organização Mundial do Comércio e o Banco Mundial. (FRIGOTTO, 2017, p. 19).

A fase do capitalismo financeiro formou uma rede mundial de controle corporativo, na qual funciona para $1 \%$ da população, mas não para o restante do planeta. As aplicações financeiras rendem acima de 5\%, enquanto o PIB mundial cresce entre $1 \%$ e $2,5 \%$ o ano (DOWBOR, 2017).

Neste cenário de financeirização de riquezas e serviços nota-se a problemática da privatização e da desvalorização do setor público, sendo possível observar uma crescente lógica mercantil no campo educacional. Este campo no Brasil sempre foi marcado por interesses diversos e contraditórios na história do país. É na década de 1930 que a educação

4 Capital financeiro refere-se à fusão de capitais monopolistas industriais aos bancários que ganha foco no estágio imperialista, que se inicia nas três últimas décadas do século XIX e percorre os séculos XX e XXI (NETTO; BRAZ, 2011). É no século XXI que se intensifica a especulação financeira, compreendida pela compra e valorização de ativos (ações de empresas) e sua venda futura com lucro sob condições de incerteza (capital de risco). 
passa a ser uma questão nacional, porém é no debate da nossa primeira LDB que se intensifica a correlação de forças entre o público e o privado (SAVIANI, 2001).

Em sua história o Brasil produziu uma sociedade desigual e violenta, ancorada na colonização e no sistema escravocrata, no qual a burguesia associou-se de forma subordinada aos centros hegemônicos do capital, não construiu uma nação autônoma e não garantiu os direitos básicos à população. Nessa acepção, a burguesia brasileira é considerada por Frigotto (2017) como antipovo, antinação e antidireito universal a qualquer setor, inclusive à escola pública de qualidade.

A educação pública brasileira tem vivido ataques nos últimos três anos, os quais demonstram a destruição das conquistas democráticas realizadas nos dois governos de Lula e de Dilma, que visaram à ampliação do direito de todos à educação (MOREIRA, 2018). Como exemplo, podemos citar a reestruturação curricular gerida pela BNCC e o empresariado; a reforma trabalhista e o projeto de reforma da previdência; venda de vagas das creches públicas para o setor privado; projetos de lei em tramitação da escola sem partido; fechamento de escolas; crescimento das escolas militares; mudança de regra da partilha do pré-sal; criação de programa assistencialista (Criança Feliz); projeto de Emenda Constitucional que prorrogou até 2023 a permissão para que a União use livremente parte de sua arrecadação (Desvinculação de Receitas da União) ampliando seu percentual de 20\% para 30\%; o exministro da educação, Mendonça Filho, no início de seu mandato solicitou o auxílio de Alexandre Frota (ator de filme pornô) e Marcelo Reis (líder do movimento Revoltados online) para discutir a área (MOREIRA, 2018).

Aliado a essas reformas há também a presença efetiva de atores privados no setor público definindo a agenda pública educativa, conceito definido por Ball e Yodell (2007) por privatização da política. Esse conceito refere-se à participação direta ou indireta de representantes do setor privado educacional na definição do debate e da agenda educativa pública. Ball e Yodell (2007) afirmam que esta é uma forma de privatização acobertada, isto é, que passa despercebida. Na agenda da educação brasileira são perceptíveis vários exemplos do conceito privatização da política, como: a atuação do Movimento pela Base Nacional Comum e Todos pela Educação. Esses movimentos são compostos por empresários brasileiros, os quais por meio de seus institutos e fundações, muitas vezes, determinam as problemáticas educacionais e propagam seu discurso - em defesa do setor privado (CAETANO, 2019). 
Ball e Yodell (2007) também trazem mais dois conceitos de privatização acobertada, denominadas por endógena e exógena. O primeiro conceito refere-se à importação de ideias, métodos e práticas do setor privado a fim de fazer com que o setor público seja cada vez mais semelhante a uma empresa em potencial comercial. A privatização exógena corresponde à participação do setor privado na oferta de seus serviços educacionais ao setor público, como concepção, gestão ou provisão de diferentes aspectos da educação pública (BALL; YODELL, 2007).

Adrião (2018) ao analisar as formas predominantes de privatização da educação básica no Brasil de 1990 a 2014, identificou a partir do mapeamento da literatura três dimensões da privatização: 1. Gestão; 2. Oferta e 3. Currículo. É nessa última dimensão apresentada por Adrião (2018) que discutimos neste artigo. Para a autora a privatização do currículo: "Trata-se mais amplamente, da transferência para o setor privado da definição do que ensinar, do como ensinar, além de processos de verificação da aprendizagem, ou seja, da definição dos desenhos curriculares" (ADRIÃO, 2018, p.20) e não apenas a compra de insumos e materiais necessários ao ensino.

As medidas de austeridade financeira no Brasil, realizadas com intensidade e grande impacto desde 2016 como a Emenda Constitucional $n^{\circ} 95^{5} \mathrm{e}$ as reformas propostas a diferentes setores sociais como a reforma trabalhista, da previdência e da educação, derivam da crise econômica que desde 2008 assola países capitalistas centrais. Esta é uma crise desigual e combinada e atingiu os países do sul, intermediários e periféricos (ANTUNES, 2017). Quanto mais a crise se aprofunda nos EUA, Europa e Japão "[...] maior é a sucção de capitais para o centro e mais intensificadas são as taxas diferenciais de exploração, seja diretamente entre o Norte e o Sul, o Leste e o Oeste, seja entre as próprias regiões e países" (ANTUNES, 2017, p.59).

Para Antunes (2017), a crise atingiu fortemente o Brasil em 2014 e início de 2015, as frações dominantes de classes chegaram ao consenso que quem pagaria a conta seriam os assalariados, portanto os cortes foram em programas sociais como Bolsa Família, seguro desemprego e nas áreas da saúde e educação. Crise esta que se aprofunda na destruição dos meios de produção e forças produtivas, eliminando gradativamente os direitos da classe trabalhadora.

${ }^{5}$ Emenda Constitucional de 15 de dezembro de 2016 altera o Ato das Disposições Constitucionais Transitórias, para instituir o Novo Regime Fiscal e dá outras providências. 
Enquanto alguns direitos sociais foram atacados com as medidas de ajuste fiscal, a esfera privada manteve seus capitais utilizando-se da verba pública. O estudo de Pinto (2016) demonstra que os recursos públicos para a manutenção da educação pública existem, contudo estão sendo encaminhados ao setor privado. Dados de sua pesquisa apresentam que para o ano de 2014 aproximadamente $\mathrm{R} \$ 32$ bilhões de reais saíram dos cofres públicos para garantir a sustentação do ensino privado. Esses recursos foram cedidos ao sistema S (Sesi, Senac, Senai, Sesc) ao Programa Nacional de Ensino Técnico e Emprego (Pronatec), a convênios de educação infantil e educação especial, à renúncia de imposto de renda, renúncia do ProUni, de entidades sem fins lucrativos e do programa FIES. Pinto (2016) detecta também que os recursos financeiros direcionados a esses setores equivalem a $56 \%$ de todo o gasto federal com a manutenção e desenvolvimento do ensino público em 2014.

\section{Grupos educacionais privados: a oferta de serviços e produtos a educação pública}

A gratuidade da educação básica pública, o acesso e a permanência em instituições de ensino é um dos compromissos da Agenda 2030 para o Desenvolvimento Sustentável, elaborada em Incheon, Coreia do Sul, em 2015, adotada por 193 Estados-membros da ONU, entre eles o Brasil. Para a Unesco (2015), o Marco de Ação da Educação 2030, menciona a educação como bem público, um direito humano fundamental, contudo nota-se o aumento da educação com fins lucrativos e diversos grupos empresariais oferecendo seus produtos a governos municipais e estaduais, a fim de alcançar suas metas de lucratividade.

Segundo Adrião et al (2015), empresas e conglomerados econômicos estão a buscar outras formas de lucrar com a educação, sem ser por meio de matrículas em escolas privadas. Esses grupos têm oferecido sistemas de ensino à rede regular pública, a fim de elevar seus lucros.

As parcerias entre as administrações municipais e o setor privado para a consecução da oferta educacional têm se disseminado no Brasil nos últimos anos. Os grupos educacionais que se destacam no Brasil, como Pearson, Somos Educação, Santillana, Positivo e Objetivo, além de oferecem seus sistemas de ensino a diversas escolas particulares do Brasil passaram a ver nos municípios brasileiros um novo mercado (ADRIÃO ET AL, 2015; ADRIÃO, 2016; ADRIÃO, 2017).

A partir da década de 2000, no Brasil, medidas desencadeadas visaram transformar a educação pública em uma alternativa para a ampliação do capital, assim sendo: “As políticas 
de cunho privatizantes foram facilitadas na realidade brasileira por alterações constitucionais", como a emenda n.19 de 1998, a qual introduziu elementos da Nova Gestão Pública, a lei federal no 9.790 de 1999 que trata das Organizações da Sociedade Civil de Interesse Público (OSCIP), a lei de responsabilidade fiscal lei $\mathrm{n}^{\circ} 101 / 2000$ e lei $\mathrm{n}^{\circ}$ 11.079/2004 das parcerias público-privadas (ADRIÃO, 2014, p. 264).

A lei $\mathrm{n}^{\mathrm{o}} 11.079 / 2004$ foi alterada pela lei $\mathrm{n}^{\mathrm{o}} 12.766 / 2012$, a qual instituiu normas gerais para licitação e contratação de parceria público-privada no âmbito da administração pública, para dispor sobre o aporte de recursos em favor do parceiro privado. Em 2017 temos a publicação da lei $\mathrm{n}^{\mathrm{o}} 13.592 / 2017^{6}$ a qual autoriza a União a participar em um fundo para financiar projetos de concessão e parcerias público-privadas (BRASIL, 2017).

Essas políticas e medidas privatizantes no Brasil derivam de um processo mais amplo, de crise do capital, o qual desde 1970 enfrenta uma queda na taxa de lucro no setor manufatureiro. A mais recente recessão e a depressão econômica ocorrida entre os anos 2007 e 2008 se arrastou até o presente ano, o queocasionou a queda no padrão de vida dos trabalhadores, crises da dívida pública, diminuição do investimento em manufatura e flexibilização quantitativa (RIKOWSKY, 2017). O capital continua a cambalear de acordo com Rikowsky (2017, p.398) devido a duas questões: primeira, o avanço da tecnologia informática mostra que a força de trabalho será deslocada para fora do setor manufatureiro e, também, fora do setor de serviços nos próximos anos em uma escala cada vez mais crescente e segunda "[...] o deslocamento do trabalho significa que não está sendo criado um valor suficiente para sustentar o desenvolvimento capitalista e a civilização”.

É em meio a essa situação sociometabólica e delicada do capital global que o financiamento estatal aparece como uma fonte milagrosa e tentadora, visada por diferentes empresas. Rikowsky (2017) apresenta que há dois tipos de privatização, a clássica/direta, a qual vende ativos públicos para alguma combinação de empresas, grupos de investidores e investidores individuais e, a segunda, é a tomada de controle da instituição, oposição a privatização direta. Na segunda forma se inserem os grupos educacionais brasileiros atuantes na educação básica, os quais tomam a direção do conteúdo das políticas educativas com a venda de sistemas de ensino, mas a propriedade permanece pública. As empresas educacionais extraem valor ${ }^{7}$ por meio desses serviços.

\footnotetext{
${ }^{6}$ Altera a lei $n^{\circ} 11.079 / 2004$, Lei no $11.578 / 2007$ e a Lei $n^{\circ} 12.712 / 2012$.

${ }^{7}$ Termo empregado por Marx na obra $O$ capital, denominado mais-valia. Segundo Marx (1987), a existência da mais-valia se dá pela exploração e expropriação da força de trabalho. A produtividade (que gera o excedente) mais a soma da força de trabalho são compreendidas por mais-valia.
} 
Esses dados indicam que as políticas educacionais para o século XXI devem ser compreendidas no domínio das transformações econômicas e políticas contemporâneas. As reformas educacionais implantadas nos países em desenvolvimento e nos países centrais decorrem da demanda do capitalismo que se reestrutura de suas crises. Ao tentarmos traçar relações entre as interfaces da ordem social capitalista e as políticas sociais de educação pautamo-nos na materialidade do século XXI, realidade constituída pelo domínio social e político do capital financeiro sustentado pelo mercado econômico, que representa a propriedade privada sob a sustentação teórica do neoliberalismo de terceira via e a economia que busca no cotidiano, a rentabilidade e a competição.

O relatório de pesquisa Sistemas de ensino privado na educação pública brasileira: consequências da mercantilização para o direito à educação $(2015)^{8}$ apresenta uma análise sobre os principais grupos educacionais envolvidos na venda de produtos às escolas públicas brasileiras. As diversas ações desses grupos têm sido em atuações nos sistemas de ensino por meio de treinamentos ou formação de professores, consultoria às prefeituras, desenvolvimento de plataformas educativas e aplicativos para alunos, professores e gestores.

De acordo com o relatório, os grupos empresariais e conglomerados econômicos têm buscado outras formas de lucrar com a educação que não exclusivamente com a oferta direta do ensino via matrículas em escolas privadas e colocam em risco os direitos humanos educacionais (ADRIÃO et al., 2015).

O relatório assevera que a aplicação de recursos públicos na compra de sistemas privados de ensino desencadeia diversos problemas à efetivação da educação pública de qualidade: a) duplicação de recursos que são ofertados gratuitamente pelo governo federal por meio do Programa Nacional do Livro e do Material Didático/PNLD, o que resulta na incapacidade de os municípios de disponibilizarem novas vagas no sistema público, em especial na faixa etária de 0 a três anos, educação de jovens e adultos e estudantes com deficiência; b) vulnerabilizam os próprios municípios de criar, gerir e implementar políticas que garantam uma educação de qualidade, já que parte das equipes técnicas e das atividades passam a ser externos aos órgãos públicos; c) os sistemas de ensino não passam por um processo de controle de qualidade por órgãos governamentais e; d) a adoção de sistemas privados de ensino inviabiliza as práticas de gestão democrática na escola pública e padroniza o trabalho docente e discente (ADRIÃO ET AL, 2015).

${ }^{8} \mathrm{O}$ relatório foi resultado de uma pesquisa realizada pelo Grupo de Estudo e Pesquisas em Políticas Educacionais (GREPPE) da Unicamp, USP e Unesp, juntamente com a Ong Ação Educativa e Open Society Foundations (ADRIÃO ET AL., 2015). 
Nesse processo de intensificação das práticas mercantilizadas no sistema público de ensino, a educação torna-se capital nesse processo, pois a receita do Estado converte-se em lucro privado. "A privatização da educação não é realmente sobre educação: trata-se de se beneficiar da receita do Estado e transformá-la em lucro" (RIKOWSKY, 2017, p.401). A privatização na educação é um estado de devir, os produtos das instituições de ensino estão em processo de capitalização, tornando-se capital ${ }^{9}$.

Importante salientar o conceito do que é sistemas privados de ensino. São pacotes e serviços oferecidos por empresas privadas a redes de ensino de Estados e municípios (ADRIÃO et al., 2015). Esses produtos podem ser materiais didáticos, como apostilas, cadernos de conteúdo, acompanhamento de supervisão de atividades docentes, elaboração de processo de avaliação interna e externa, modelos de gestão, orientação a pedagogos e gestores, plataformas educacionais (a distância) a professores e alunos e consultorias educacionais.

O Quadro 1 apresenta os principais grupos educacionais que atuam na educação básica e destaca o período de fundação do grupo, bem como os serviços prestados e os sistemas de ensino ofertados.

Quadro 1. Grupos educacionais privados e seus serviços e produtos

\begin{tabular}{|c|c|c|c|}
\hline $\begin{array}{l}\text { Grupo/ } \\
\text { Fundação }\end{array}$ & Serviços & $\begin{array}{c}\text { Sistemas de } \\
\text { ensino }\end{array}$ & Produtos \\
\hline Século XIX & $\begin{array}{l}\text { Atendimento a educação infantil } \\
\text { Ensino fundamental } \\
\text { Soluções digitais e livros } \\
\text { universitários; } \\
\text { Materiais distintos para estudantes } \\
\text { da educação básica } \\
\text { Material virtual e impresso de } \\
\text { orientação a educadores; } \\
\text { assessorias com visitas às escolas } \\
\text { Oferta de avaliações aplicadas } \\
\text { presencialmente e à distância, } \\
\text { com suporte técnico para as } \\
\text { equipes governamentais. }\end{array}$ & $\begin{array}{l}1 \text { NAME } \\
2 \text { COC by } \\
\text { Pearson } \\
3 \text { Dom Bosco by } \\
\text { Pearson } \\
4 \text { Atitude by } \\
\text { Pearson }\end{array}$ & $\begin{array}{l}1 \text { Wizard by Pearson } \\
\text { (franquia) } \\
2 \text { Yázigi (franquia) } \\
3 \text { Skill (franquia) } \\
4 \text { Quatrum } \\
5 \text { Smartz }\end{array}$ \\
\hline
\end{tabular}

${ }^{9}$ Para Marx (2011), capital é uma relação social e de produção pertencente a uma formação histórica particular. Sua ideia é anterior ao sistema capitalista, mas é nesta sociedade que a produção do capital prevalece. 


\begin{tabular}{|c|c|c|c|}
\hline & $\begin{array}{l}\text { Escola de idiomas } \\
\text { Materiais profissionais para } \\
\text { psicólogos }\end{array}$ & & testes psicológicos \\
\hline $\begin{array}{c}\text { Vasta/ } \\
\text { Somos } \\
\text { Educação } \\
2019\end{array}$ & $\begin{array}{l}\text { Atendimento à educação infantil } \\
\text { Ensino fundamental; } \\
\text { Ensino médio; } \\
\text { Cursos preparatórios para exames } \\
\text { vestibulares; } \\
\text { Curso preparatório para } \\
\text { concursos; } \\
\text { Escolas de ensino de idiomas } \\
\text { RedBalloon; } \\
\text { Assessoria pedagógica; } \\
\text { Formação de professores }\end{array}$ & $\begin{array}{l}1 \text { Anglo } \\
2 \mathrm{pH} \\
3 \mathrm{Ser} \\
4 \text { Geo } \\
5 \text { Maxi } \\
6 \text { Ético } \\
7 \text { Rede Cristã } \\
8 \text { Pitágoras }\end{array}$ & $\begin{array}{l}1 \text { Editora Ática } \\
2 \text { Editora Scipione } \\
3 \text { Editora Saraiva } \\
4 \text { Editora Atual } \\
\text { Monitoria online } \\
\text { para alunos dos } \\
\text { sistemas de ensino. } \\
\text { Formação de } \\
\text { liderança (o líder em } \\
\text { mim). } \\
\text { English Star } \\
\text { Plurall } \\
\text { Profs }\end{array}$ \\
\hline $\begin{array}{c}\text { Prisa/ } \\
\text { Santillana } \\
1960\end{array}$ & $\begin{array}{l}\text { Material didático para educação } \\
\text { infantil; fundamental, médio, pré- } \\
\text { vestibular e idioma; } \\
\text { Atendimento às escolas e } \\
\text { secretarias de educação; } \\
\text { Oficinas e formação continuada } \\
\text { para docentes; } \\
\text { Assessoria para avaliação } \\
\text { educacional e institucional; } \\
\text { Plataforma educacional }\end{array}$ & $\begin{array}{c}\text { Uno } \\
\text { Internacional } \\
\text { (Unoi) }\end{array}$ & $\begin{array}{l}\text { Editora Moderna } \\
\text { Editora Salamandra } \\
\text { Editorial Reichmond } \\
\text { Editora Santillana } \\
\text { Español } \\
\text { Avalia Educacional } \\
\text { SmartLab } \\
\text { Educate Bilingual } \\
\text { Program }\end{array}$ \\
\hline Objetivo & $\begin{array}{l}\text { Material didático elaborado para } \\
\text { educação infantil, fundamental e } \\
\text { médio; } \\
\text { Material de apoio para a equipe } \\
\text { responsável pela gestão escolar; } \\
\text { Material virtual de orientação para } \\
\text { professores; } \\
\begin{array}{l}\text { Encontros pedagógicos e cursos } \\
\text { modulares para professores; }\end{array} \\
\text { Avaliação institucional e de }\end{array}$ & $\begin{array}{l}\text { Sistema de } \\
\text { ensino Objetivo }\end{array}$ & Editora e gráfica \\
\hline
\end{tabular}




\begin{tabular}{|c|c|c|c|}
\hline & $\begin{array}{lll}\text { resultados dos } & \text { estudantes } & \text { em } \\
\text { testes para } & \text { elaboração } & \text { de } \\
\text { diagnóstico. } & & \end{array}$ & & \\
\hline Positivo & $\begin{array}{l}\text { Livro didático para educação } \\
\text { infantil, ensino fundamental e } \\
\text { ensino médio; } \\
\text { Orientação e material para } \\
\text { professores; } \\
\text { Assessoria pedagógica a docentes } \\
\text { e equipes técnicas das secretarias } \\
\text { de educação para orientar a } \\
\text { implantação do sistema; } \\
\text { Formação continuada para } \\
\text { docentes e equipes técnicas; } \\
\text { Ferramenta de gestão das } \\
\text { informações educacionais; } \\
\text { Avaliações de desempenho de } \\
\text { estudantes, segundo os padrões da } \\
\text { Prova Brasil. }\end{array}$ & $\begin{array}{l}\text { Sistema de } \\
\text { Ensino Aprende } \\
\text { Brasil -público } \\
\text { Sistema de } \\
\text { ensino Positivo } \\
\text { (particular) } \\
\text { Conquista } \\
\text { Solução } \\
\text { Educacional } \\
\text { (particular) }\end{array}$ & $\begin{array}{l}\text { Colégios próprios } \\
\text { Cursos pré- } \\
\text { vestibulares } \\
\text { Universidade } \\
\text { Editora Positivo } \\
\text { Editora Aprende } \\
\text { Brasil } \\
\text { Gráfica Positivo } \\
\text { Posigraf } \\
\text { Positivo Tecnologias }\end{array}$ \\
\hline $\begin{array}{l}\text { Etapa } \\
1970\end{array}$ & $\begin{array}{l}\text { Educação Básica } \\
\text { Pré-vestibular } \\
\text { Ensino Superior }\end{array}$ & $\begin{array}{l}\text { Etapa } \\
\text { Etapa Público }\end{array}$ & $\begin{array}{l}\text { Colégio próprio } \\
\text { Colégio } \\
\text { Internacional }\end{array}$ \\
\hline 1973 & $\begin{array}{l}\begin{array}{l}\text { Educação infantil, ensino } \\
\text { fundamental e médio; }\end{array} \\
\begin{array}{l}\text { Cursos de graduação e pós } \\
\text { graduação }\end{array} \\
\text { Material didático para educação } \\
\text { infantil, fundamental e médio. } \\
\text { Escola de profissão } \\
\text { Plataforma virtual para gestores, } \\
\text { professores e alunos }\end{array}$ & $\begin{array}{l}\text { Opet soluções } \\
\text { educacionais }\end{array}$ & $\begin{array}{l}\text { Editora Opet } \\
\text { Programa } \\
\text { empreender } \\
\text { Momento Cidadania } \\
\text { Cidade Mirim } \\
\text { Programa de } \\
\text { informação } \\
\text { profissional ao } \\
\text { aluno/PIPA }\end{array}$ \\
\hline
\end{tabular}

Fonte: Sítios eletrônicos oficiais dos grupos educacionais citados, relatório de pesquisa do grupo GREPPE e Ação Educativa e Souza (2019). Elaboração: autoras.

A Pearson é uma empresa educacional multinacional britânica, suas origens datam de 1724, quando Thomas Longman fundou a Longman, contudo a Pearson foi fundada em 1844 por Samuel Pearson em Yorkshire na Inglaterra. A primeira empresa de Samuel foi de construção denominada de S. Pearson and Son. Em 1880 já era uma das maiores construtoras 
do mundo. Hoje a empresa atua no ramo educacional e está presente em mais de 70 países (PEARSON, 2020).

No Brasil suas unidades ficam em São Paulo/SP, Campinas/SP e Ribeirão Preto/SP. O grupo Pearson atua na educação básica, ensino superior com soluções digitais e livros universitários, possui franquias de escolas de idiomas, diversos sistemas de ensino para a escola privada e um exclusivo para a escola pública denominado de núcleo de apoio a municípios e Estados, o NAME, o qual iniciou suas atividades em 1999 no Brasil estabelecendo parcerias pedagógicas com o ensino público em algumas cidades do estado de São Paulo. A partir do sucesso da implantação nesses locais, hoje o NAME se estende por 140 municípios brasileiros. O NAME produz material didático a escolas públicas da educação infantil, ensino fundamental e Educação de Jovens e Adultos (EJA), plataforma digital para alunos, professores e gestores e suporte pedagógico com eventos presenciais e visitas a escolas. O site do NAME afirma que as escolas que são suas parceiras aumentaram o nível do IDEB (PEARSON, 2020).

O grupo Prisa/Santillana lidera o mercado de comunicação, conteúdos culturais e educacionais nos países de língua espanhola e portuguesa. Santillana está presente em 24 países e no Brasil atua desde 2001 e possui diversos empreendimentos, tais como a fundação Santillana, Editoras (Moderna, Salamandra, Richmond, Santillana Español), Unoi Educação, Sistema Farias Brito de ensino, Avalia educacional (assessoria e consultoria), Smart Lab (plataforma) e programa bilingue - Educate Bilingual Program. A Fundação Santillana se dedica a fomentar atividades às escolas públicas e privadas em cursos de formação, seminários e oficinas para professores e gestores, publicação e divulgação de obras de avaliação e políticas públicas educacionais e parcerias na viabilização de projetos de incentivo à leitura, cultura e cidadania (SANTILLANA, 2020).

A Salamandra, Richmond e Moderna são editoras que produzem livros didáticos, literários, pedagógicos e e-books. Ao procurar no site do grupo Santillana encontra-se um sistema de ensino exclusivo para escolas públicas, denominado Uno Público, contudo o site está com última data de atualização, em 2016. Em contato telefônico com a central do Uno Público, a atendente disse que há somente um sistema de ensino, o Uno Interacional e ele não atende escolas da rede pública (SANTILLANA, 2020).

A empresa Avalia Educacional do grupo Santillana é influente nas parcerias com escolas públicas e privadas no desenvolvimento de avaliações educacionais que analisam o desempenho de alunos da educação básica em diferentes áreas de conhecimento. Um dos 
produtos dessa empresa é a plataforma Aprova Brasil, que consiste em um projeto de intervenção para alcance de habilidades e competências exigidas nas avaliações educacionais (Prova Brasil, Provinha Brasil e Avaliação nacional do rendimento escolar - Ana). O produto é composto de material didático de apoio ao professor e simulados. Na plataforma digital as escolas inserem as respostas dos estudantes e a mesma apresenta as habilidades e competências que os alunos dominam e outras que precisam ser melhoradas. A partir dela é gerado um relatório individual dos alunos, "tornando" possível que o professor intervenha pedagogicamente nas necessidades detectadas pela plataforma.

Aprova Brasil, pode ser solicitada pelos entes federados pela iniciativa do PAR 90 Plano de Ações Articuladas10 por meio do Sistema Integrado de Monitoramento, Execução e Controle do Ministério da Educação - Simec. Isto nos mostra o quanto é facilitada a entrada do setor privado nas políticas educacionais e a drenagem de recursos públicos a essas empresas. Adrião et al (2015, p.29) alega que a relação entre o setor corporativo e público é imbricado de ações lucrativas e não lucrativas “[...] que impactam diretamente a tomada de decisão política".

Destacamos também o papel da editora Moderna, pertencente ao grupo Prisa/Santillana. Em 2019 ela liderou o número de títulos adquiridos pelo Programa Nacional do Livro e do Material Didático (PNLD), o qual fornece livros aos alunos da educação básica pública brasileira e a instituições comunitárias, confessionais ou filantrópicas sem fins lucrativos conveniadas com o poder público. O quadro dois apresenta a quantidade de títulos adquiridos e o valor total da compra pelo Fundo Nacional de Desenvolvimento da Educação FNDE.

Quadro 2. As sete editoras com mais títulos adquiridos no PNLD de 2019

\begin{tabular}{|c|c|c|}
\hline Editoras & Títulos Adquiridos & Valor Total R\$ \\
\hline 1 Moderna & 334 & $245.474 .157,13$ \\
\hline 2 Edições SM & 232 & $114.721 .621,41$ \\
\hline 3 FTD & 226 & $143.397 .824,93$ \\
\hline 4 Saraiva & 216 & $97.612 .280,70$ \\
\hline 5 Ática & 208 & $215.334 .753,96$ \\
\hline 6 Editora do Brasil & 167 & $72.238 .911,16$ \\
\hline 7 Scipione & 92 & $60.424 .046,87$ \\
\hline
\end{tabular}

Fonte: FNDE, 2019. Elaboração: autoras.

\footnotetext{
${ }^{10}$ Para mais detalhes consultar Decreto ${ }^{\circ}$ 6.094, de 24 de abril de 2007 e Resolução/CD/FNDE ${ }^{\circ} 14$ de 8 de
} junho de 2012. 
As editoras Ática, Saraiva e Scipione que estão entre as sete com mais títulos adquiridos no PNLD de 2019 pertencem a mesma marca, Vasta/Somos Educação. Além dos sistemas privados de ensino ofertados a escola pública e privada, a Vasta/Somos Educação arrecada parte dos recursos públicos pelo edital do PNLD conforme valor descrito no quadro 2. Já a editora Positivo teve 36 títulos adquiridos no PNLD de 2019, com um valor total de R\$ 12.584.048,85 (doze milhões, quinhentos e oitenta e quatro mil, quarenta e oito reais e oitenta e cinco centavos).

Somos Educação é um grupo que oferece amplo portfólio de soluções educacionais: editoras, sistemas de ensino, escolas próprias, cursos preparatórios, cursos de idiomas e desenvolvimento de tecnologias para a educação. Sua fundação segundo site do grupo, se dá no ano de 201011, quando as editoras Ática e Scipione e o sistema de ensino SER, pertencentes ao Grupo Abril, foram cindidos para formar a Abril Educação. À época, essa separação possibilitou aproveitar a tradição e o pioneirismo na produção de livros didáticos e paradidáticos das editoras e explorar o potencial do segmento de educação (SOMOS EDUCAÇÃO, 2020).

Em julho de 2011, com intuito de ampliar seu negócio, a companhia decidiu captar recursos no mercado a partir da oferta pública inicial de ações (IPO). Do termo inglês Inicial Public Offer (IPO), significa que a empresa realizou a sua primeira oferta pública, abrindo seu capital ao mercado (BRASIL, 2018b). Em 2014, a Abril Educação conclui a migração para o mercado da Bolsa de Valores, mercadorias e Futuros S.A (BM\&FBOVESPA). No ano seguinte, 2015, adquiriu a Abrilpar Participações, pertencente à família Civita. Em junho de 2015, a empresa deixa a cor verde e a árvore símbolo da sua logomarca e adotou nova identidade visual que simboliza a fase atual da nova companhia: a Somos Educação. A logomarca sugere uma conexão com o que há de mais evidente nos dias de hoje: o mundo colaborativo.

Em março de 2017, a Somos Educação adquiriu o AppProva, uma plataforma de testes e diagnósticos para alunos, escolas e instituições de ensino superior e, no fim de 2017, comprou a Stoodi (plataforma de aulas de preparação para o Enem e vestibular) e a Livro Fácil, sítio de venda de livros didáticos, literários, atlas, dicionários, acessórios escolares e uniformes,ampliando mais a plataforma educacional para o ensino básico.

\footnotetext{
${ }^{11}$ Contudo, a Abril Educação que se torna Somos Educação pertencia à família Civita e sua origem data de 1960 . O fundador do Grupo Abril foi Victor Civita (1907-1990). Seu filho Roberto Civita, cria a Fundação Victor Civita na década de 1980. Mas é no final dos anos de 1960 que o grupo desenvolve os primeiros materiais educacionais para o Movimento Brasileiro de Alfabetização (Mobral) e a partir de 1990 o grupo adquire as editoras Ática e Scipione (GRUPO ABRIL, 2018).
} 
A empresa, Somos que já foi da família Victor Civita, hoje pertence a Cogna Educação, antiga Kroton, a qual se dividiu em 4 frentes: Kroton, Platos, Saber e Vasta Educação/Somos Educação. No site da Cogna, a empresa afirma ter mais de 50 anos de tradição e pioneirismo. A holding oferece soluções e serviços tanto para o segmento B2B (business to business/empresa para empresa) como para o B2C (empresa para pessoa física). A Somos educação, controlada pela Tarpon gestora foi comprada pela Kroton em 2018, por meio da holding Saber por 4,5 bilhões de reais (VEJA, 2018). Com a aquisição da Somos, a educação básica passa a representar $28 \%$ da receita líquida do grupo Cogna.

O grupo Cogna atende mais de 2,4 milhões de estudantes de todo o Brasil, da Educação Básica ao Ensino Superior, sendo 1 milhão de alunos atendidos diretamente e 1,4 milhão de estudantes por meio das escolas e instituições de ensino parceiras. Suas atividades e programas sociais geram um impacto de mais de $\mathrm{R} \$ 431,1$ milhões à sociedade, ajudando a transformar as comunidades onde está inserida. (COGNA, 2018, RELATÓRIO DE SUSTENTABILIDADE).

A Somos educação atua no ramos de cursos preparatórios para exames vestibulares, para concursos, escolas de ensino de idiomas Red Ballon, assessoria pedagógica, formação de professores, possui diversos colégios, possui plataforma digital, monitoria online para alunos dos sistemas de ensino, 3 editoras (Ática, Scipione, Saraiva/Atual), 8 sistemas de ensino (Anglo, pH, Ser, Geo, Maxi, Ético, Pitagorás e rede Cristã), conta com soluções complementares com a formação de liderança (o líder em mim), English Star, Plurall, Profs e plataforma educacional - PAR.

A Vasta/Somos Educação não possui um sistema de ensino específico para a educação básica pública, contudo tem ofertado a prefeituras o sistema Maxi de ensino. No estado do Paraná em 2019, a empresa esteve presente em 18 municípios, são eles: Arapuã, Bela Vista do Paraíso, Cafeara, Centenário do Sul, Cidade Gaúcha, Guapirama, Guaraci, Conselheiro Mairinck, Jaguapitã, Lunardeli, Mirasselva, Nova Fátima, Nova Olímpia, Porecatu, Prado Ferreira, Sertanópolis, Florestópolis e Lupionópolis (SOUZA, 2019).

Fundado em 1965, o grupo Objetivo atua na educação básica e na preparação para vestibulares. A rede de escolas conveniadas contempla mais de 450 municípios, sendo mais de 200 escolas no estado de São Paulo e parte delas no Japão. Essa rede de escolas privadas possui aproximadamente 430 mil alunos (OBJETIVO, 2020). O sistema Objetivo Municipal de Ensino/SOME, oferta material didático e atendimento pedagógico desde o ano 2000 as 
escolas públicas. Segundo site eletrônico do grupo, o SOME contempla mais de 100.000 mil alunos em diversos municípios do país (OBJETIVO, 2020).

O grupo Positivo, criado em 1972 com a oferta de cursos pré-vestibulares, cresce gradativamente ampliando seus serviços na área de colégios, educação superior, indústria de computadores e tecnologias educacionais. O nome positivo foi criado pelo professor de biologia Samuel Ramos Lago, o mesmo propôs o nome e a arte do dedo e da "mãozinha" em sua logomarca, os contornos finais da arte foram do artista plástico paranaense Luis Carlos Retamozzo (POSITIVO, 2020).

No início da década de 1980, o grupo Positivo teve sua primeira experiência internacional em parceria com a Construtora Camargo Correa, os professores das Escolas Positivo ministraram aulas aos filhos de brasileiros que trabalhavam na construção da usina hidrelétrica de Gúri, na Venezuela. O grupo Positivo também atuou na administração de escolas nas hidrelétricas do Paraná, Salto Osório, Salto Santiago e Guaíra, em Santa Catarina na hidrelétrica de Itá, na usina de Porto Primavera, São Paulo e nos projetos Jari e Cadam, no Estado do Pará (POSITIVO, 2020).

Em 1991, o Sistema Positivo de Ensino já tinha mais de 200 mil alunos em escolas conveniadas pelo Brasil. Esteve presente na oferta de serviços educacionais nas empresas da indústria papeleira no Paraná, nos municípios de Arapoti (empresa Inpacel), Jaguariaíva (Pisa) e Telêmaco Borba (Klabin). Em 2000 ocorre a construção do campus universitário no bairro Campo Comprido em Curitiba. Na época, o grupo possuía 17 faculdades que compunham o UnicenP (centro universitário Positivo), estas se instalaram em único lugar, hoje a Universidade Positivo oferta cursos de graduação (licenciaturas, bacharelados), especialização, programas de mestrado e doutorado (POSITIVO, 2020).

Em 2010, a Editora Positivo lançou a série ouro e prata do dicionário Aurélio de língua portuguesa em homenagem ao centenário de nascimento de seu criador, Aurélio Buarque de Holanda Ferreira. Neste mesmo ano ocorreu a internacionalização da Positivo informática juntamente com a empresa BGH argentina, a união entre as duas empresas deu origem a uma outra Informática Fueguina S.A.

O grupo Positivo possui um sistema de ensino exclusivo para as escolas públicas, denominado, Aprende Brasil, o qual contempla livro didático impresso e em versão digital, assessoria pedagógica, aprende Brasil On (plataforma virtual de aprendizagem) e sistemas de avaliação (hábile) e de gestão (Sistema de monitoramento educacional do Brasil). 
Em 2019 o grupo vendeu seu sistema de ensino e outras soluções educacionais destinadas a escolas privadas ao grupo Arco Educação (G1, 2019). A Universidade Positivo que possui oito campis no estado do Paraná e 33 mil alunos, foi vendida em 4 de março de 2020 ao grupo Cruzeiro do Sul Educacional, quinto maior grupo de ensino superior no país em termos de quantidade de alunos ativos (CRUZEIRO DO SUL, 2020).

O Grupo Educacional Etapa inicia sua trajetória com um curso pré-vestibular em 1970 e em 1982 funda o Colégio Etapa. Segundo informações do site do grupo, após a fundação do colégio este “[...] começa a chamar a atenção pelos prêmios que passa a conquistar. Inicialmente são as medalhas da Academia de Ciências do Estado de São Paulo. Em seguida, os prêmios tornam-se nacionais. A partir de 1986 os alunos do Colégio Etapa começam a representar o país em competições internacionais" (ETAPA, 2019, s/p). Na década de 1990 o grupo leva suas ideias para outras escolas por meio do Sistema Didático Etapa, oferecendo programação e material a escolas de São Paulo e outros estados. Em 2006 o grupo chega ao ensino superior e cria a Escola Superior de Engenharia e Gestão/ESEG.

O grupo possui um sistema exclusivo para a educação pública, denominado Etapa público, este oferta materiais a educação infantil e as series iniciais do ensino fundamental (cadernos multidisciplinares, cadernos de inglês e arte). Os materiais didáticos ofertados pelo sistema destinam-se a alunos, professores e equipe de gestão. Para esta é oferecido materiais estratégicos para obtenção dos melhores resultados acadêmicos, instrumentos gerenciais para acompanhamento dos cursos e sugestões para a avaliação do aprendizado (ETAPA, 2019).

O Grupo Educacional Opet foi fundado em 25 de janeiro de 1973 pelo professor José Antonio Karam. Atualmente possui a seguinte estrutura organizacional: Centro Universitário/UniOpet (Pós-Graduação e Graduação presencial), Colégio (infantil ao médio), Opetwork Escola de Profissão, Editora, Sistema de Ensino e Instituto de Educação e Cidadania (OPET, 2019).

Iniciou sua trajetória com cursos de capacitação profissional, em 1985 cria o colégio Opet com os primeiros cursos médios técnicos e em 1993 funda a editora Opet e inaugura o colégio unidade Iguaçu na cidade de Curitiba. Em 1998 inaugura outro colégio unidade centro cívico na mesma cidade e um ano depois, inicia as operações da faculdade Opet. No ano de 2002 lança o centro de pós graduação Opet, em 2010 implementa a modalidade de educação a distância (EAD) e em 2017 é autorizado como Centro Universitário/UniOpet pelo MEC.

A Editora Opet, fundada em 1993 em Curitiba, era responsável pela produção dos livros e apostilas utilizados pelos estudantes e professores do colégio e dos cursos técnicos 
oferecidos pelo Grupo Educacional Opet na capital paranaense. "A qualidade desses materiais didáticos chamou a atenção de outras escolas privadas e de redes públicas de ensino, que desejavam contar com recursos semelhantes em suas próprias salas de aula” (OPET, 2019).

Diante desse interesse, a Editora Opet passou a oferecer seus serviços a outras instituições de ensino, o que levou a um aprimoramento dos materiais e à busca por recursos pedagógicos avançados. Foi a partir dessa ideia que nasceu o Sistema de Ensino Opet, hoje Opet Soluções Educacionais. Em 2015, a Editora Opet adquiriu o SEFE - Sistema Educacional Família e Escola, um sistema de ensino também fundado em Curitiba. Em 2019, a Editora Opet atuou com dois selos educacionais: Opet Soluções Educacionais, dirigido às escolas privadas, e SEFE, voltado às escolas públicas. Juntos, os dois selos chegam a 340 mil estudantes, 17 Estados e Distrito Federal, que recebem livros, formações pedagógicas, coleções e ferramentas tecnológicas para uma educação humana, relevante e cidadã (EDITORA OPET, 2019).

Até 2019, o site da editora Opet propagava que o SEFE estava presente em 120 municípios brasileiros, 17 estados, atingia 75 mil estudantes do ensino fundamental e 80 formadores pedagógicos. O pacote SEFE oferece duas propostas ao ensino público para a educação infantil, a coleção Entrelinhas e a coleção Brincar e Pensar.

Com o exposto no Quadro 01, observa-se que há ampla rede de produtos e serviços educacionais e alguns deles destinados à educação pública, como o Sistema Name (Pearson), Aprende Brasil (Positivo), Sistema SOME (Objetivo), Aprova Brasil (Santillana), Sistema educacional família e escola (SEFE) e Sistema Etapa público. Esses sistemas de ensino e plataforma de indicadores, são ofertados e adotados na maioria das vezes pelas prefeituras, responsáveis pela etapa da educação infantil e series iniciais do ensino fundamental.

Adrião et al $(2015$, p.91) apontam que a municipalização repentina e mal planejada do ensino fundamental nas últimas duas décadas exibiu a precariedade de muitas das administrações locais, "[...] gerando um promissor mercado para assessorias privadas nos campos pedagógico e de gestão". Em alguns municípios, grupos empresariais chegam a assumir a orientação da política de educação do município, criando situações que violam aspectos importantes do direito à educação, como a adaptabilidade e a acessibilidade (ADRIÃO et al., 2015).

Um dos argumentos que as empresas/grupos educacionais oferecem a gestão pública de ensino é a ênfase na qualidade. Em maio de 2015, no Fórum Mundial de Educação, ocorrido em Incheon, Coreia do Sul, os 160 países participantes se comprometeram com a 
efetuação da agenda E2030, com abrangência em específico para a educação, o objetivo número 4, denominado de ODS4 e expresso no documento resultante do Fórum, a Declaração de Incheon (2015). A Organização das Nações Unidas para a Educação, a Ciência e a Cultura (UNESCO) ficou como a responsável para liderar e coordenar a agenda política E2030 na América Latina e o Caribe (UNESCO, 2018).

A declaração de Incheon/Marco de Ação da Educação 2030 enfatiza em seu documento que as nações devem buscar e alcançar a qualidade da educação. No Brasil a discussão da qualidade leva a

[...] duas opções radicalmente diferentes. A primeira opção, infelizmente, a mais provável, consiste em acentuar a definição restrita de qualidade no sentido de reforçar e generalizar o ensino padronizado (apostilado) no país. Tanto os estudantes quanto suas famílias não têm outras prioridades além de obter boas notas em testes nacionais e internacionais para passar no vestibular, o que pode ser considerado o auge de uma educação bancária, para citar o famoso conceito de Paulo Freire. O Vestibular aparece como o momento da verdade, em que é lançado o destino escolar de um jovem, ou seja, um teste que determina o resultado de 12 a 13 anos de uma vida escolar. (AKKARI, 2017, p.952-953).

Esta cultura de testes, enraizada nas escolas do Brasil, convence o estudante desde a sua mais tenra idade “[...] que não há igualdade, nem a solidariedade, nem o respeito à diferença, mas a concorrência e o mérito individual. Cada um é responsável por si mesmo, ninguém é responsável pelos outros e não há lugar na escola para todos" (AKKARI, 2017, p.953).

O discurso meritocrático de ascensão social por meio da educação e a busca pela vaga na melhor universidade faz com que os grupos educacionais privados ganhem acesso junto às secretarias de educação municipais para ofertar a qualidade de ensino tão propalada, com vistas a alcançar o quase inalcançável Ideb (Índice de Desenvolvimento da Educação Básica).

Nota-se que a educação é um meio de valor, uma mercadoria altamente rentável a empresários. Essa lógica de convênios e a compra de produtos do setor privado pela máquina pública é uma das formas de garantir o "[...] processo de acumulação do capital e de estabelecimento de um consenso que torna possível a reprodução do injusto sistema de classes” (MÉSZÁROS, 2008, p.15).

Uma das principais funções que a educação formal tem assumido nas nossas sociedades é produzir conformidade e consenso. O mercado tem visto os espaços educacionais como meios funcionais à lógica do consumo e do lucro (valor). Na sociedade do 
capital, a educação e o trabalho se subordinam a essa dinâmica, da mesma forma que em uma sociedade onde se universalize o trabalho, isto é, uma sociedade onde todos se tornem trabalhadores, somente aí se universalizará a educação (MÉSZÁROS, 2008).

A autoeducação de iguais e a autogestão da ordem social reprodutiva não podem ser separadas uma da outra. É necessário romper com a lógica do capital “[...] se quisermos contemplar a criação de uma alternativa educacional significativamente diferente" (MÉSZÁROS, 2008, p.27). O autor declara que mesmo na sociedade capitalista deve-se lutar por uma educação pública que qualifique para vida. Contudo, esta tarefa vai muito além dos espaços das salas de aula, dos gabinetes e dos fóruns acadêmicos.

Além das orientações de agências internacionais como o Marco de ação para a Educação 2030, proposto pela Unesco, Banco Mundial e outras agências da ONU e das empresas educacionais que objetivam ampliar seu mercado, destaca-se também o golpe institucional ocorrido no Brasil em 2016, que não representou retrocesso somente no regime democrático, mas nos direitos sociais e no delineamento das políticas e gestão da educação.

Nesse contexto, a diminuição drástica dos recursos públicos para a educação pública evidenciou a intenção do governo em aprofundar políticas de terceirização e privatização. No Estado de Goiás, a exemplo, tentou-se impor a transferência da gestão de escolas públicas para entidades privadas, muitas delas sem idoneidade, experiência ou capacidade em gestão pública. A terceirização da escola pública elimina gradativamente os direitos trabalhistas dos profissionais da educação e a gestão democrática da escola (PARANÁ, 2016).

E a educação, nesse contexto neoliberal de mercantilização, é abordada pelas parcerias público-privadas, as quais têm definido o conteúdo da educação. Executam sua proposta em redes internacionais e nacionais do capital. Peroni e Caetano (2012), em seu estudo sobre a influência do terceiro setor na educação, declara que a direção do conteúdo das políticas educativas é repassada para o setor privado, mas a propriedade permanece pública. A autora verifica que a presença do privado mercantil tem definido a educação pública, o conteúdo curricular tem sido alvo da correlação de forças.

A gestão escolar no Brasil não demonstra um histórico democrático e a privatização é algo naturalizado em nossa cultura (PERONI; CAETANO, 2012). O conteúdo da educação é um mercado em expansão, livros, uniformes, tecnologias, sistemas de ensino e materiais diversos contemplam a ação dos grandes grupos educacionais. Peroni e Caetano (2012, p.10) afirmam que o governo federal desenvolveu programas educacionais, estabeleceu parcerias com municípios e escolas públicas diretamente, consolidando assim um novo modelo de 
gestão de políticas públicas e sociais, simultaneamente “[...] em que tem promovido o envolvimento de outras instituições consideradas "terceiro setor" na implementação de programas sociais no nível local e nacional, tais como as organizações não - governamentais (ONGs) e as organizações da sociedade civil de interesse público (OSCIPs), que influenciam a gestão da educação e da escola".

A autora enfatiza ainda que as instituições do terceiro setor para a área da educação influenciam as políticas públicas por meio da divulgação de novas ideias, de acordos e novas práticas, participando com êxito nas reformas educativas. Muitos são os “[...] empresários que se unem aos tomadores de decisão e formadores de opinião sobre a política educacional e se legitimam perante a sociedade" (PERONI; CAETANO, 2012, p.10). É o caso de Viviane Senna, Coordenadora do Instituto Ayrton Senna e coordenadora executiva do Todos pela Educação, Jorge Gerdau Johannpeter, conselheiro de governança do Movimento Todos pela Educação, Luís Norberto Pascoal, presidente da empresa Dpaschoal, Luiz Paulo Montenegro, vice-presidente do Grupo Ibope entre muitos outros (TPE, 2016).

Todos esses sujeitos empresários e influentes na economia nacional integram o Movimento Todos pela Educação, movimento este de cunho gerencialista criado em 2006 que propõe a mobilização do setor privado e das organizações sociais para atuar junto ao Estado na oferta da educação.

A atuação do Movimento Todos Pela Educação é um exemplo concreto com que Gentili (2010) traz em sua discussão sobre a desordem neoliberal, a violência de mercado e o destino da educação das maiorias. O autor alega que a escola pública é desintegrada por meio de uma série de estratégias privatizantes e de uma política de reforma cultural que pretende apagar do horizonte ideológico da sociedade a possibilidade de uma educação democrática, pública e de qualidade para as maiorias.

Seguindo a mesma direção da discussão da desintegração da educação pública, Dale (2010) destaca que a privatização está distante de ser o único processo de realização das aspirações da Nova Direita ${ }^{12}$ em educação. Tratar da questão público/privado para o autor é pouco para compreender as complexidades e mudanças que os sistemas educacionais vêm sendo submetidos.

\footnotetext{
${ }^{12}$ Casimiro (2018) afirma que a Nova Direita é a dominação burguesa organizada em aparelhos privados de hegemonia, a qual se reinventa na sua forma de dominação. Objetiva implantar o mais do mesmo: a dominação, o enxugamento de direitos e a garantia do lucro. A Nova Direita pode ser representada por institutos, centros de estudo, revistas e think tanks, que se articulam em ações pelo país e internacionalmente.
} 
Diversas combinações de financiamento, fornecimento e regulamentação se caracterizam "[...] como mecanismos de mercado na economia de política social responsável pela heterogeneidade dos mercados educacionais que se proliferam no mundo ocidental" (DALE, 2010, p.131). A introdução do mercado no projeto de despolitização da educação é uma estratégia da nova direita, a fim de reduzir a legitimação, o fardo que o sistema educacional representa para o Estado (DALE, 2010).

Em meio a este cenário de inserção de produtos privados em escolas públicas, observamos também os recursos públicos transferidos aos mercados educacionais, o que denominamos de capitalização da educação. "A privatização da educação não é essencialmente a respeito da educação em si” (RIKOWSKY, 2017, p.410). E essa tendência está a ganhar força na última década com o Estado atuando na administração da educação enquanto um bem público e uma commodity.

A compra de sistemas de ensino por estados e municípios podem ser caracterizados como processos de privatização, isto significa a intensificação de ações que visam à fragilidade do sistema público de ensino (corpo docente, estudantes, financiamento escasso, gestão pouco democrática). A defesa por uma educação pública estatal, gratuita, laica e de qualidade soa como um insulto e medo ao segmento privado, o medo de se ferir a "liberdade" de ensino.

\section{Considerações finais}

Ao discutir sobre a atuação de grupos educacionais privados envolvidos na oferta de seus produtos a educação básica pública e a influência dessa transmissão de recursos financeiros públicos ao setor privado, pode-se constatar que a educação pública para as empresas educacionais é um mercado em expansão. Estes grupos usam o discurso naturalizado do serviço privado como sinônimo de eficiência e qualidade e disseminam as boas chances que os municípios possuem de alcançarem os índices adequados nas avaliações nacionais e internacionais.

Observou-se que entre as sete empresas analisadas neste trabalho - Pearson, Somos Educação, Positivo, Objetivo, Santillana, Etapa e Opet, seis delas (Pearson, Objetivo, Positivo, Santillana, Etapa e Opet) apresentam serviços e produtos destinados exclusivamente para a educação pública. A compra de serviços educacionais pela máquina pública gera o fortalecimento do discurso que o privado possui qualidade e acima de tudo aflora a 
privatização da educação. As políticas educacionais estão sendo construídas por novas organizações e atores sociais os quais têm atuado de modo global por meio de políticas transnacionais (BALL, 2014).

Verificou-se também que a compra de produtos pelo sistema público desfavorece a autonomia das instituições de ensino na elaboração de seu trabalho pedagógico, enfraquece o debate sobre planejamento, homogeneíza os conteúdos e currículos escolares e induz ao conformismo generalizado de docentes, discentes e funcionários de forma a subordinar às exigências da ordem estabelecida.

A adoção de sistemas privados de ensino pela rede pública é uma forma de privatização disfarçada, pois essa ação convence as instituições de ensino, a equipe escolar e a sociedade que a alternativa para alcançar a qualidade da educação é o modelo educacional proposto pelas empresas educacionais citadas, Pearson, Somos Educação, Santillana, Objetivo, Positivo, Etapa e Opet. Por fim, averiguou-se, também, que a preocupação desse mercado educacional, representado pelas empresas expostas nessa análise, não é garantir as necessidades humanas e nem de fato melhorar a qualidade da educação, mas prioritariamente assegurar a extração de mais valor nos diferentes setores de sua produção.

\section{REFERÊNCIAS}

ADRIÃO, T. M. F. Escolas charters nos EUA:contradições de uma tendência proposta para o Brasil e suas implicações para a oferta da educação pública.Revista Educação e Filosofia, Uberlândia, v. 28, n. especial, p.263-282, 2014. Disponível em: http://www.seer.ufu.br/index.php/EducacaoFilosofia/article/view/24613/15303. Acesso em: 6 jan. 2016.

ADRIÃO, T.; GARCIA, T.; BORGUI, R. F.; BERTAGNA, R. H.; XIMENES, G. P. S. Sistemas de Ensino Privados na Educação Pública Brasileira: Consequências da Mercantilização para o Direito à Educação. Ação Educativa; Greppe; Open Society foundations, 2015. Disponível em:

$<$ http://www.observatoriodaeducacao.org.br/images/pdfs/sistemas_privados.pt.pdf $>$. Acesso em: 8 abr. 2018.

ADRIÃO, T. et al. Grupos empresariais na educação básica pública brasileira: limites à efetivação do direito à educação. Educação e Sociedade, Campinas. v. 37. n.134. p. 113-131. Jan-mar.; 2016.

ADRIÃO, T. M. F. privatização dos processos pedagógicos: Grupos editoriais e os negócios na educação básica. IN: MARINGONI, G. (Org.) O negócio da educação. São Paulo: Olho D’agua e Fepesp, 2017. p.129-144. 
ADRIÃO, T. M. F. Dimensões e formas da privatização da educação no Brasil: caracterização a partir de mapeamento de produções nacionais e internacionais. Currículo sem fronteiras, v.18, n.1, p.8-28, jan./abr.2018.

AKKARI, A. A agenda internacional para educação 2030: consenso "frágil" ou instrumento de mobilização dos atores da educação no século XXI?.Revista Diálogo Educacional, Curitiba, v. 17, n. 53, p. 937-958, 2017.

ANTUNES, R. A era das contrarrevoluções e o novo Estado de Exceção. In: A crise da democracia brasileira. LUCENA, C.; PREVITALI, F. S.; LUCENA, L. Uberlândia: Navegando publicações, 2017. p.53-61.

BALL, S.; YODELL, D. Privatización encubierta en la educación pública. In:

Internacional de laeducación. Bruselas, 2007.

Disponível em:

〈https://www.joanmayans.com/privatizacion_encubierta_de_la_educacion_publica.pdf $>$. Acesso em 23 jan. 2019.

BALL, S. Educação Global S.A: novas redes de políticas e o imaginário neoliberal. Tradução de Janet Bridon. Ponta Grossa: UEPG, 2014.

BRASIL. LEI No13.529, de 4 de dezembro de 2017. Dispõe sobre a participação da União em fundo de apoio à estruturação e ao desenvolvimento de projetos de concessões e parcerias público-privadas. 2017. Disponível em: $<$ http://www.planalto.gov.br/ccivil_03/_Ato20152018/2017/Lei/L13529.htm>. Acesso em:23.jan.2019.

BRASIL. Histórico do financiamento estudantil no Brasil. FNDE. 2018 a.

http://www.fnde.gov.br/acesso-a-informacao/institucional/area-deimprensa/noticias/item/4752-hist\%C3\%B3rico>. Acesso em 19 ago.2018.

BRASIL. Portal do investidor. 2018b. Disponível em: $<$ http://www.investidor.gov.br/menu/Menu_Investidor/ofertas/ofertas_publicas.html $>$. Acesso em 25 jan. 2018.

CADE. Superintendência Geral conclui parecer sobre operação entre Kroton e Estácio. Conselho administrativo de defesa econômica. 2017. Disponível em:

<http://www.cade.gov.br/noticias/superintendencia-geral-conclui-parecer-sobre-operacaoentre-kroton-e-estacio. $>$ Acesso em: 19 ago. 2018.

CAETANO, M. R. A Base Nacional Comum Curricular e os sujeitos que direcionam a política educacional brasileira. Revista Contrapontos eletrônica, v. 19, n.2, Jan./Dez. 2019, p.132-141. Revista Contrapontos I Eletrônica I Vol. 19 I No 2 I Itajaí I JAN-DEZ 2019.

CASIMIRO, F. H. C. A nova direita: aparelhos de ação política e ideológica no Brasil contemporâneo. São Paulo: Expressão popular, 2018.

COGNA EDUCAÇÃO. Relatório de sustentabilidade 2018. Informação disponível em: http://ri.kroton.com.br/wp- 
content/uploads/sites/44/2019/06/190610_Kroton_RS2018_naveg\%C3\%A1vel_.pdf. Acesso em 24 dez. 2019.

\section{CRUZEIRO DO SUL. A Cruzeiro do Sul educacional concretiza aquisição da}

Universidade Positivo. 4/3/2020. Disponível em:

https://www.cruzeirodosuleducacional.edu.br/fatos_relevantes/a-cruzeiro-do-sul-educacionalconcretiza-aquisicao-da-universidade-positivo. Acesso em 11 mar.2020.

DALE, R. O marketing do mercado educacional e a polarização da educação. In: GENTILI, Pablo (Org.) Pedagogia da exclusão: Crítica ao neoliberalismo em educação. 17.ed. Petrópolis: Vozes, 2010. p.129-158.

DOURADO, L. F. Políticas e gestão da educação superior no Brasil: múltiplas regulações e controle. Revista RBPAE, v.27, n. 1, p.53-65, jan./abr.2011.

DOWBOR, L. A era do capital improdutivo: a nova arquitetura do poder, sobre dominação financeira, seqüestro da democracia e destruição do planeta. São Paulo: Autonomia Literária, 2017.

FNDE. PNLD 2019. Valores de aquisição por editora. Disponível em: https://www.fnde.gov.br/index.php/programas/programas-do-livro/pnld/dados-estatisticos. Acesso em 5 fev.2020.

FRIGOTTO, G. A gênese das teses do Escola sem Partido: esfinge e ovo da serpente que ameaçam a sociedade e a educação.In: FRIGOTTO, G. (Org). Escola "sem" partido: esfinge que ameaça a educação e a sociedade brasileira. Rio de Janeiro:UERJ, LPP, 2017. p.13-34.

GENTILI, P. Adeus a escola pública: a desordem neoliberal, a violência do mercado e o destino da educação das maiorias. In: GENTILI, Pablo (Org.) Pedagogia da exclusão: Crítica ao neoliberalismo em educação. 17.ed. Petrópolis: Vozes, 2010.p.215-237.

GRUPO ABRIL. Quem somos. Disponível em: <http://abril.assineabril.com.br/grupoabril/> Acesso em: 10 ago. 2018.

G1. Grupo Positivo assina compromisso de venda de sistema de ensino para a Arco Educação por R\$ 1,65 bilhão. 2019. Disponível em:

https://g1.globo.com/pr/parana/noticia/2019/05/08/grupo-positivo-assina-compromisso-devenda-de-sistema-de-ensino-para-a-arco-educacao-por-r-165-bilhao.ghtml. Acesso em 4 jan.2020.

INEP. Censo escolar 2017: matrícula inicial. 2017a. Disponível em: <http://inep.gov.br/web/guest/matricula-inicial $>$. Acesso em: 10 ago. 2018.

INEP. Censo da educação superior: Notas estatísticas. 2017b. Disponível em: <http://download.inep.gov.br/educacao_superior/censo_superior/documentos/2018/censo_da educacao_superior_2017-notas_estatisticas2.pdf. Acesso em: 23 jan. 2019.

MARX, K. Teorias da mais valia. São Paulo: Bertrand Brasil, 1987. v. 1, Livro 4. 
MARX, K. O capital. Livro I. 2.ed. São Paulo: Boitempo editorial, 2011.

MÉSZAROS, I. A educação para além do capital. 2.ed. São Paulo: Boitempo, 2008.

MOREIRA, J. A. da S. Reformas educacionais e políticas curriculares para a educação básica:prenúncios e evidências para uma resistência ativa. Germinal: Marxismo e educação em debate, Salvador, v.10, n.2, p.199-213, Ago.2018. Disponível em:

$<$ https://portalseer.ufba.br/index.php/revistagerminal/article/view/27355 >. Acesso em 8.set.2018.

NETTO, José Paulo; BRAZ, Marcelo. Economia política: uma introdução crítica. 7. ed. São Paulo: Cortez, 2011.

OBJETIVO. Grupo Objetivo. 2020. Disponível em: <http:

//www.objetivo.br/some/propostas.asp.>. Acesso em: 4 jan.2020.

PARANÁ. Governo revoga sistema de avaliação básica do MEC. 2016. Disponível em:<http://appsindicato.org.br/index.php/governo-temer-revoga-sistema-de-avaliacao-daeducacao-basica-do-mec/>. Acesso em: 12 jul. 2016.

PEARSON. 2020. Disponível em: 〈https://br.pearson.com/>. Acesso em: 4 jan.2020. PERONI, Vera; CAETANO, Maria R. Redefinições no papel do Estado: parcerias público/privadas e a gestão da educação. 2012. Disponível em:

<http://www.ucs.br/etc/conferencias/index.php/anpedsul/9anpedsul/paper/viewFile/1015/972 >. Acesso em: 12 jul. 2016.

PINTO, José M. de Rezende. Uma análise da destinação dos recursos públicos, direta ou indiretamente, ao setor privado de ensino no Brasil. Revista Educação e Sociedade, Campinas, v.37, $\mathrm{n}^{\circ} 134$, p.133-152, jan.-mar., 2016. Disponível em: <http://www.scielo.br/pdf/es/v37n134/1678-4626-es-37-134-00133.pdf>. Acesso em: 12 jul. 2016.

POSITIVO. Grupo Positivo. 2020. Disponível em:〈http://www.positivo.com.br/>. Acesso em: 4 jan.2020.

RIKOWSKI, G. Privatização em educação e formas de mercadoria. Revista Retratos da escola/Escola de formação da Confederação Nacional dos Trabalhadores em Educação (Esforce), Brasília, v.11, n.21, jul./dez.2017.

SANTILLANA. Grupo Santillana. 2020. Disponível em: <https://www.gruposantillana.com.br>. Acesso em: 4 jan.2020.

SAVIANI, D. Antecedentes históricos da nova LDB. A nova lei da educação: trajetória, limites e perspectivas. Campinas, SP: Autores associados, 2001. p.1-34.

SOMOS EDUCAÇÂO. Grupo Somos Educação. 2018. Disponível em: $<$ http://www.somoseducacao.com.br/>. Acesso em 8 abr. 2018. 
SOUZA, T. G. Mercantilização da educação básica no Paraná. Relatório parcial de pesquisa. Programa de pós graduação em educação/PPE. Universidade Estadual de Maringá, 2019.

TPE. Todos Pela Educação. 2016. Disponível em:

<http://www.todospelaeducacao.org.br/quem-somos/quem-faz/?tid_lang=1>. Acesso em: 12 set. 2016.

UNESCO. Declaração de Incheon Educação 2030: rumo a uma educação de qualidade inclusiva e equitativa e à educação ao longo da vida para todos. Fórum Mundial de Educação 2015. Disponível em: http://unesdoc.unesco.org/images/0023/002331/233137POR.pdf.

Acesso em: 12 abr. 2018.

VEJA. Cade aprova compra da Somos Educação pela Kroton por R\$ 4,5 bilhões. 19 de setembro de 2018. Disponível em: https://veja.abril.com.br/economia/cade-aprova-comprada-somos-educacao-pela-kroton-por-r-45-bilhoes/. Acesso em: 16. jan. 2019.

\section{SOBRE AS AUTORAS:}

\section{Thaís Godoi de Souza}

Doutoranda em Educação pelo Programa de Pós Graduação em Educação da Universidade Estadual de Maringá (UEM). Professora do curso de Educação Física UEM/CRV. Membro do Grupo de Estudos e Pesquisa em Políticas Educacionais, Gestão e Financiamento da Educação (GEPEFI/CNPq). E-mail: tgsouza2@uem.br

(iD http://orcid.org/0000-0002-8447-5454

\section{Jani Alves da Silva Moreira}

Pós doutora em Educação pela Universidade Federal do Paraná (UFPR), com estágio pósdoutoral na Universidade de Salamanca. Professora Adjunta do Departamento de Teoria e Prática da Educação (DTP/UEM) e do Programa de Pós Graduação em Educação (PPE/UEM). Líder do Grupo de Estudos e Pesquisa em Políticas Educacionais, Gestão e Financiamento da Educação (GEPEFI/CNPq). E-mail: professorajani@ hotmail.com

(iD) http://orcid.org/0000-0002-3008-0887. 